Bull. Mater. Sci., Vol. 35, No. 3, June 2012, pp. 291-295. (c) Indian Academy of Sciences.

\title{
A theoretical study on interaction of proline with gold cluster
}

\author{
SANDHYA RAI, N V SURESH KUMAR and HARJINDER SINGH* \\ International Institute of Information Technology-Hyderabad, Gachibowli, Hyderabad 500 032, India
}

MS received 27 March 2012

\begin{abstract}
Interaction of proline with gold cluster was studied using density functional theory (DFT). Two types of mixed basis sets UB3LYP/6-311++G $\cup$ LANL2MB and UB3LYP/6-311++G $\cup$ LANL2DZ were used for optimization of complex structures. Proline interacts with gold cluster either through one anchor bond, N-Au or an anchor bond O-Au associated with a non-conventional O-H...Au hydrogen bond. Among these interactions, higher tendency for interaction is seen with Au cluster through amide terminal. Natural bond orbital analysis (NBO) is used to substantiate the results.
\end{abstract}

Keywords. Proline; gold nanoparticles; interaction energy; DFT; NBO.

\section{Introduction}

Gold nanoparticles have attracted much attention in material science due to their biocompatibility and ability to conjugate with organic and biomolecular systems (Shafai et al 2007; Shukla et al 2008) which make them suitable for use in biochemical sensing and detection (Storhoff et al 1998; Riboh et al 2003; Shafer-Peltier et al 2003). Several experimental and theoretical investigations are focused on the interaction of gold with amino acids and DNA. Small clusters formed by metals such as $\mathrm{Cu}, \mathrm{Ag}$ and $\mathrm{Au}$ have been studied experimentally (Bucher et al 1988; Cheeseman and Eyler 1992; Lian et al 1993; Lee and Ervin 1994) using resonant twophoton ionization, photoelectron spectroscopy and Raman spectroscopy. Theoretical studies on neutral (Balasubramanian and Liao 1991, 1992; Lee et al 2003; Zheng et al 2003; Soule de Bas et al 2004; Xiao and Wang 2004; Walker 2005; Yuan et al 2005; Xiao et al 2006), anionic (Furche et al 2002; Hakkinen et al 2002; Kim et al 2003; Lee et al 2003; Niemietz et al 2003; Agrawal et al 2004; Remacle and Kryachko 2005) and cationic clusters (Gilb et al 2002; Weis et al 2004; Fielicke et al 2005; Remacle and Kryachko 2005; Walker 2005) formed by $\mathrm{Au}$ and $\mathrm{Ag}$ were mostly devoted to provide geometry, binding energy and spectroscopic details.

Detection of $\alpha$-amino acids is an important area of research in proteomics (Pakiari and Jamshidi 2007). Major difficulty associated with the detection of $\alpha$-amino acids in proteins using chemosensors is their structural similarity (Ait-Haddou et al 2001). Thomas et al reported selective detection of micromolar concentrations of cysteine/glutathione by exploiting the interplasmon coupling of Au nanorods (Sudeep et al 2005). Further theoretical studies such as adsorption of the cysteine on the $\mathrm{Au}(111)$ surface (Felice et al 2003), interaction of glycine and cysteine with $\mathrm{Au}_{3}$ (Pakiari and Jamshidi 2007) and interaction of

\footnotetext{
*Author for correspondence (harjinder.singh@iiit.ac.in)
}

small gold clusters with $x$ DNA base pairs (Sharma et al 2009) have motivated us to carry out a theoretical study on interaction of proline with gold nanoparticles. Proline is unique among the natural amino acids as its side chain is cyclized to the backbone, which gives exceptional conformational rigidity to the proteins. It is commonly found as first residue of an alpha helix, beta sheets and turns (Moradi et al 2009).

In the present work, we have attempted to study the nature of interaction of small gold cluster composed of three gold atoms with neutral amino acid, proline, in order to locate preferable binding sites of gold atoms. The cluster size of $\mathrm{Au}_{3}$ is considered for the following reason: A recent CarParinello ab initio molecular dynamics study demonstrated that the optimal size of gold cluster to mimic conjugation of gold nanowires with organic molecules is composed of three to four bonded gold atoms (Krüger et al 2002). We have carried out density functional theory (DFT) (Kohn et al 1996) based quantum chemical analysis of the interactions.

\section{Methodology}

GAUSSIAN03 (Frisch et al 2003) suite of quantum chemical programs was used for carrying out all electronic and structural calculations. Initial geometries of proline complexed with $\mathrm{Au}_{3}$ cluster were generated by placing the cluster atoms near amide and carboxylic groups of proline. This was done by using GaussView (Dennington et al 2003) software. The geometries were optimized using density functional theory with UB3LYP functional in gas phase. Hybrid B3LYP exchange-correlation functional was used in recent computational studies on gold clusters tagged with natural amino acids, glycine and cysteine (Pakiari and Jamshidi 2007) and natural DNA bases and base pairs (Kryachko and Remacle 2005a, b; Kumar et al 2006) and its use is justified in the present context. It should be noted that for larger 
systems where stacking may be possible, dispersion interactions should be accounted for carefully and the level of calculations as presented here may not suffice. For our systems mostly stabilized by hydrogen bonding, the missing dispersion component and missing BSSE correction approximately compensate each other (Černý and Hobza 2007). Basis set 6-311++G was used for atoms of the amino acid and two different basis sets, LANL2MB (Hehre et al 1969) and LANL2DZ were applied for the gold atoms. The LANL2MB and LANL2DZ basis sets use 11-valence electron pseudopotential for $\mathrm{Au}$ atoms and interaction of $[\mathrm{Xe}] 4 f$ inner electrons are considered as relativistic effective core potential (RECP) (Pakiari and Jamshidi 2007; Sharma et al 2009). These basis sets differ in treating outer $5 d^{10} 6 s^{1}$ valence orbitals (11 valence electrons) of $\mathrm{Au}$, where LANL2DZ uses a double- $\zeta$ basis set and LANL2MB employs a minimal basis set (Sharma et al 2009).

Vibrational analysis was carried out on optimized geometries of the complexes and real frequencies were obtained in all cases. Interaction energy, $E_{\mathrm{int}}$, was corrected for zero point vibrational energy (ZPVE). It was calculated using the following equation:

$$
E_{\text {int }}=E_{\text {complex }}-\left(E_{\text {proline }}+E_{\mathrm{Au}_{3}}\right),
$$

where $E_{\text {complex }}, E_{\text {proline }}$ and $E_{\mathrm{Au}_{3}}$ are zero point corrected electronic energies of proline complexed with the gold cluster, proline and gold cluster, $\mathrm{Au}_{3}$, respectively.

Natural bond orbital (Read et al 1985) (NBO) analysis was employed to calculate charge transfer interactions in the complexes.

\section{Results and discussion}

The basis sets, UB3LYP/6-311++G $\cup$ LANL2MB and UB3LYP/6-311++G $\cup$ LANL2DZ used for the optimization of the structures are referred to as $\mathbf{1}$ and $\mathbf{2}$, respectively in the subsequent text. Figures and tables labeled ' $n$ ' are in the main text and 'Sn' are in the supporting information. Optimized geometries of the proline tagged with gold cluster, obtained using the basis sets $\mathbf{1}$ and $\mathbf{2}$, are shown in figures 1 and 2, respectively. Coordinates of optimized species are given in tables S1-S7. Nitrogen of amide and oxygen of carboxylic groups can donate their lone pair electrons to gold atoms. Gold can also act as proton acceptor and forms nonconventional H-bonds with amide and hydroxyl groups of the amino acid. Interaction of the amino acid with gold may be either monodentate or bidentate. The bidentate interaction involves a non-conventional H-bonding interaction.

\subsection{Structure and energetic aspects of complex}

Proline interacts through the amide group $(\mathrm{Au}-\mathrm{N})$ and carboxylic group ( $\mathrm{Au}-\mathrm{O}$ and $\mathrm{Au} . . \mathrm{H}-\mathrm{O})$; the corresponding complexes with gold cluster are referred to as $\mathrm{Pro}^{-\mathrm{Au}_{3}}$ (a)

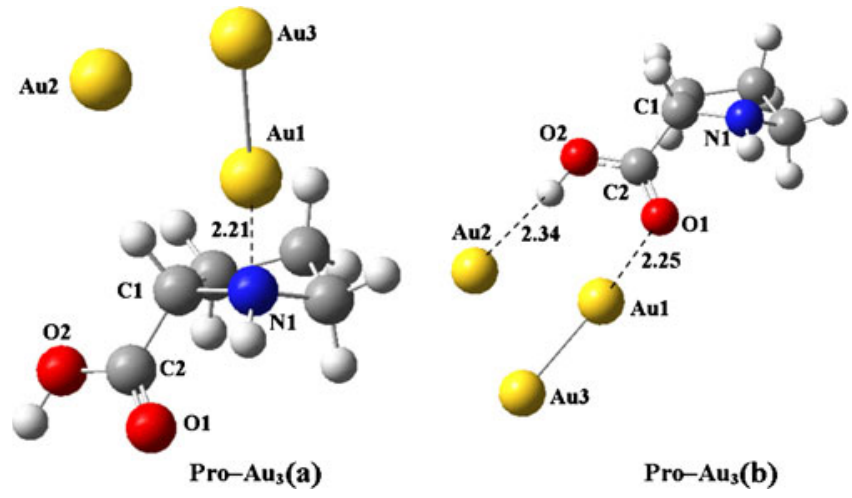

Figure 1. Geometries of proline tagged with $\mathrm{Au}_{3}$ at its amide terminal, Pro- $\mathrm{Au}_{3}(\mathbf{a})$, and at carboxylic terminal, pro- $\mathrm{Au}_{3}$ (b), optimized at UB3LYP/6-311++G $\cup$ LANL2MB level of theory. Bond lengths are given in angstrom. Atom numbering scheme for atoms at active sites is shown.
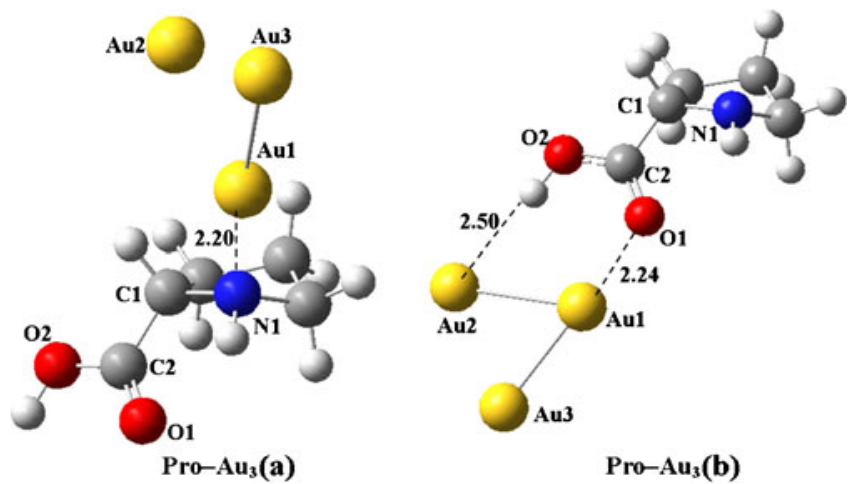

Figure 2. Geometries of proline tagged with $\mathrm{Au}_{3}$ at its amide terminal, Pro- $\mathrm{Au}_{3}$ (a), and at carboxylic terminal, pro- $\mathrm{Au}_{3}$ (b), optimized at UB3LYP/6-311++G $\cup$ LANL2DZ level of theory. Bond lengths are given in angstrom. Atom numbering scheme for atoms at active site is shown.

and Pro- $\mathrm{Au}_{3}(\mathbf{b})$, respectively in the subsequent text. Magnitudes of various bond lengths and interaction energies are shown in table 1. Additional structural details and absolute energies of the geometries are shown in table S8.

The structure of $\mathrm{Pro}_{-} \mathrm{Au}_{3}(\mathbf{a})$ has a monodentate interaction through Au1-N1 with gold cluster. As expected, the Au1-N1 bond length $(2 \cdot 20-2 \cdot 21 \AA)$ does not change much as the basis set is varied, but the interaction energy changes from -36.45 to $-28.80 \mathrm{kcal} / \mathrm{mol}$ when the gold atoms are treated with LANL2DZ as compared to the case with LANL2MB basis set. This can be attributed to use of higher level of basis set. The enhanced basis set considers inner Au electrons as RECP and uses a double zeta basis set to treat valence electrons.

Significant change is observed in the dihedral angle O1$\mathrm{H}-\mathrm{N} 1-\mathrm{C} 1$ (referred to as $\phi$ ) in isolated proline and Pro- $\mathrm{Au}_{3}$ (a). In isolated proline the angle $\phi$ is $20 \cdot 6^{\circ}$, in $\mathrm{Pro}^{-\mathrm{Au}_{3}}$ (a) optimized at the level of basis sets $\mathbf{1}$ and $\mathbf{2}$, it is $13.9^{\circ}$ and $15 \cdot 0^{\circ}$, respectively (table S8). The reduction in the angle 
Table 1. Geometric and energetic features of proline complexed with $\mathrm{Au}_{3}$ clusters.

\begin{tabular}{|c|c|c|c|c|c|c|}
\hline Basis set & Molecule & $R(\mathrm{X}-\mathrm{Au})(\AA)$ & $\Delta R(\mathrm{X}-\mathrm{A})(\AA)$ & $\angle \mathrm{X}-\mathrm{A} \ldots \mathrm{B}$ (degrees) & $\Delta v(\mathrm{X}-\mathrm{A})\left(\mathrm{cm}^{-1}\right)$ & $E_{\text {int }}(\mathrm{kcal} / \mathrm{mol})$ \\
\hline \multirow[t]{3}{*}{1} & Pro- $-\mathrm{Au}_{3}(\mathbf{a})$ & $\mathrm{N} 1-\mathrm{Au} 1(2 \cdot 21)$ & $\mathrm{N} 1-\mathrm{H}(0 \cdot 01)$ & N1-H... O1 $\left(110 \cdot 6^{\circ}\right)$ & N1-H(-112·95) & $-36 \cdot 45$ \\
\hline & Pro- $-\mathrm{Au}_{3}(\mathbf{b})$ & O1-Au1(2·25) & $\mathrm{C} 2=\mathrm{O} 1(0 \cdot 03)$ & & $\mathrm{C} 2=\mathrm{O} 1(-116 \cdot 85)$ & $-24 \cdot 66$ \\
\hline & & $\mathrm{O} 2 \mathrm{H} \ldots \mathrm{Au} 2(2 \cdot 34)$ & $\mathrm{O} 2-\mathrm{H}(0 \cdot 01)$ & $\mathrm{O} 2-\mathrm{H} . . \mathrm{Au} 2\left(174 \cdot 1^{\circ}\right)$ & $\mathrm{O} 2-\mathrm{H}(-616 \cdot 30)$ & \\
\hline \multirow[t]{3}{*}{2} & Pro- $-\mathrm{Au}_{3}(\mathbf{a})$ & $\mathrm{N} 1-\mathrm{Au}_{1}(2 \cdot 20)$ & $\mathrm{N} 1-\mathrm{H}(0 \cdot 01)$ & N1-H. . O1 $\left(110.9^{\circ}\right)$ & $\mathrm{N} 1-\mathrm{H}(-117 \cdot 46)$ & $-28 \cdot 80$ \\
\hline & Pro- $-\mathrm{Au}_{3}(\mathbf{b})$ & O1-Au1(2·24) & $\mathrm{C} 2=\mathrm{O} 1(0 \cdot 03)$ & & $\mathrm{C} 2=\mathrm{O} 1(-111 \cdot 31)$ & $-17 \cdot 19$ \\
\hline & & $\mathrm{O} 2 \mathrm{H} \ldots \mathrm{Au} 2(2 \cdot 50)$ & $\mathrm{O} 2-\mathrm{H}(0 \cdot 01)$ & O2-H. . Au2 $\left(177 \cdot 2^{\circ}\right)$ & $\mathrm{O} 2-\mathrm{H}(-477 \cdot 00)$ & \\
\hline
\end{tabular}

$R(\mathrm{X}-\mathrm{Au})=$ length of anchoring bond or non-conventional hydrogen bonds $(\mathrm{X}=\mathrm{O}, \mathrm{N}$ and $\mathrm{H}) ; \Delta R(\mathrm{X}-\mathrm{A})=$ difference between bond lengths of $\mathrm{N}-\mathrm{C}, \mathrm{O}-\mathrm{C}$ and $\mathrm{N}-\mathrm{H}$ in complexed and isolated fragments; $\angle \mathrm{X}-\mathrm{A} . . . \mathrm{B}=\mathrm{H}$-bond angle (conventional or non-conventional); $\Delta v(X-$ $A)=$ difference between frequency of $\mathrm{N}-\mathrm{C}, \mathrm{C}-\mathrm{O}, \mathrm{N}-\mathrm{H}$ and $\mathrm{O}-\mathrm{H}$ bonds in complexed and isolated fragments; $E_{\text {int }}=$ interaction energy; Magnitude of all parameters except interaction energy is given in parenthesis; Basis sets 1 and 2 refer to UB3LYP/6-311++G $\cup$ LANL2MB and UB3LYP/6-311++G $\cup$ LANL2DZ, respectively (see text).

Table 2. NBO analysis of donor acceptor interactions in proline tagged with gold cluster, optimized using basis sets $\mathbf{1}$ and $\mathbf{2}$ in gas phase.

\begin{tabular}{|c|c|c|c|}
\hline \multirow[b]{2}{*}{ Molecule } & \multirow[b]{2}{*}{ Charge transfer interaction } & \multicolumn{2}{|c|}{$E(2)(\mathrm{kcal} / \mathrm{mol})$} \\
\hline & & $\begin{array}{l}\text { In complex optimized } \\
\text { with basis set } \mathbf{1}\end{array}$ & $\begin{array}{l}\text { In complex optimized } \\
\text { with basis set } 2\end{array}$ \\
\hline \multirow[t]{3}{*}{ Pro- $-\mathrm{Au}_{3}(\mathbf{a})$} & $n_{\mathrm{O} 1} \rightarrow \sigma_{\mathrm{N} 1-\mathrm{H}}^{*}$ & 0.55 & $0 \cdot 54$ \\
\hline & $n_{\mathrm{Au} 1} \rightarrow \sigma_{\mathrm{N} 1-\mathrm{H}}^{*}$ & $0 \cdot 34$ & $0 \cdot 39$ \\
\hline & $n_{\mathrm{Au} 3} \rightarrow \sigma_{\mathrm{N} 1-\mathrm{Au} 1}^{*}$ & $74 \cdot 12$ & $60 \cdot 96$ \\
\hline \multirow[t]{4}{*}{ Pro-Au $\mathrm{Au}_{3}$ (b) } & $n_{\mathrm{O} 1} \rightarrow \sigma_{\mathrm{Au} 1-\mathrm{Au} 3}^{*}$ & $5 \cdot 35$ & $5 \cdot 61$ \\
\hline & $n_{\mathrm{O} 1} \rightarrow \sigma_{\mathrm{Au} 1-\mathrm{Au} 2}^{*}$ & $5 \cdot 31$ & - \\
\hline & $n_{\mathrm{Au} 2} \rightarrow \sigma_{\mathrm{O} 2-\mathrm{H}}^{*}$ & 1.87 & 1.63 \\
\hline & $n_{\mathrm{O} 1} \rightarrow n_{\mathrm{Au} 1}^{*}$ & $8 \cdot 42$ & 8.09 \\
\hline
\end{tabular}

increases proximity of hydrogen of amide with carbonyl oxygen (distance O...H is reduced by $0 \cdot 22 \AA$ ). Angle O1...H$\mathrm{N} 1$ in $\mathrm{Pro}_{-\mathrm{Au}_{3}}$ (a) optimized at $\mathbf{1}$ and $\mathbf{2}$ levels of basis set is $110.6^{\circ}$ and $110.9^{\circ}$, respectively, i. e. angle is increased by about $9 \cdot 0^{\circ}$ (tables 1 and S8). This data confirm existence of a weak $\mathrm{H}$-bonding interaction $\mathrm{N} 1-\mathrm{H}$... O 1 . This interaction is further substantiated by red shift in the stretching mode of N1-H bond vibration. The frequency of N1-H bond in the complex structure optimized at $\mathbf{1}$ and $\mathbf{2}$ levels of basis set is red shifted as compared to isolated fragment, proline, i. e. $\Delta v$, which is -112.95 and $-117.46 \mathrm{~cm}^{-1}$, respectively. Overall the results indicate that proline exhibits a favourable interaction with the $\mathrm{Au}_{3}$ cluster through its amide end. This favourable binding induces an intramolecular H-bonding interaction in proline.

The other structure Pro- $\mathrm{Au}_{3}$ (b) has a bidentate interaction through Au1-O1 and $\mathrm{Au} 2 \ldots \mathrm{H}-\mathrm{O} 2$ bonds with gold cluster. In this case, the magnitude of Au1-O1 bond length (2.24-2.25 $\AA$ ) does not change much but the Au2... H distances in Au2...H-O2 (2.34 and $2.50 \AA$, respectively) are significantly different for structures optimized at $\mathbf{1}$ and $\mathbf{2}$ levels of basis set, respectively. Interaction energy in the two cases, -24.66 and $-17.19 \mathrm{kcal} / \mathrm{mol}$, respectively differ significantly. The $\mathrm{C} 2=\mathrm{O} 1$ and $\mathrm{O} 2-\mathrm{H}$ bond distances increased by 0.03 and $0.01 \AA$, respectively after interaction with gold for both choices of basis sets. The stretching mode of $\mathrm{C} 2=\mathrm{O} 1$ bond in Pro- $\mathrm{Au}_{3}$ (b) undergoes a red shift, i.e. $\Delta v=-116.85 \mathrm{~cm}^{-1}$ with respect to isolated proline when the complex structure is treated with basis set $\mathbf{1}$. The magnitude of $\Delta v$ decreased to $-111.31 \mathrm{~cm}^{-1}$ when basis set 2 is used for the molecule. On the other hand, when optimized with basis set $\mathbf{1}$, stretching mode of $\mathrm{O} 2-\mathrm{H}$ shows a large red shift of $616.30 \mathrm{~cm}^{-1}$ due to the non-conventional $\mathrm{H}$-bonding interaction, $\mathrm{O} 2-\mathrm{H} . . . \mathrm{Au} 2$. The magnitude of $\Delta v$ is reduced to $-477.00 \mathrm{~cm}^{-1}$ when basis set 2 is used for optimization of the molecule. This value is close to the values reported for same kind of interaction seen in glycine and cysteine tagged with $\mathrm{Au}_{3}$ (Pakiari and Jamshidi 2007).

A comparison of interaction energies of the complexes Pro- $\mathrm{Au}_{3}$ (a) and Pro- $\mathrm{Au}_{3}$ (b) indicates that Pro- $\mathrm{Au}_{3}$ (a) possesses highest affinity to the gold cluster. Significantly, both the basis sets $\mathbf{1}$ and $\mathbf{2}$ confirmed the trend. This is in agreement with the earlier results of Pakiari and Jamshidi (2007) on glycine- $\mathrm{Au}_{3}$ and $\mathrm{Cysteine-} \mathrm{Au}_{3}$ linkages which concluded that amine end of the amino acids has more affinity to the gold cluster.

\subsection{Natural bond orbital analysis}

Natural bond orbital (NBO) analysis has been performed on the geometries in order to quantify noncovalent donoracceptor interactions between gold cluster and the amino 
acid. Such interactions result in transfer of occupancy from the localized bonding orbital to empty non-Lewis orbitals. The study provides additional insights into interaction of the amino acid with gold cluster. Results of second order perturbation theory analysis of the Fock matrix for donor and acceptor delocalization interactions observed in the complex structures optimized using basis sets $\mathbf{1}$ and $\mathbf{2}$ are given in table 2 . The discussion mainly refers to geometries optimized with basis set $\mathbf{2}$.

Stabilization energy, $E^{(2)}$, of charge transfer interaction, $n_{\mathrm{Au} 3} \rightarrow \sigma_{\mathrm{N} 1-\mathrm{Au} 1}^{*}$ in $\mathrm{Pro}^{-\mathrm{Au}_{3}}$ (a) is significant as the magnitude is $60.96 \mathrm{kcal} / \mathrm{mol}$. Charge transfer from lone pair of Au1 to antibonding orbital of $\mathrm{N}-\mathrm{H}$ is low, as the value of $E^{(2)}$ for the interactions is $0.39 \mathrm{kcal} / \mathrm{mole}$ in the geometry. This is an obvious result since hydrogen of amide does not lie between Au1 and N1. Additionally it forms a hydrogen bond interaction with carbonyl oxygen of proline, the energy, $E^{(2)}$, of which is $0.54 \mathrm{kcal} / \mathrm{mol}$.

NBO analysis of interactions in other complex structure Pro- $\mathrm{Au}_{3}$ (b) confirms existence of stabilizing interactions. Energy of non-conventional O2-H... Au2 hydrogen bonding interaction is $1.63 \mathrm{kcal} / \mathrm{mol}$, indicating a smaller amount of charge transfer from lone pair of $\mathrm{Au} 2$ to $\sigma_{\mathrm{O} 2-\mathrm{H}}^{*}$.

A comparison of magnitudes of $E^{(2)}$ shown by the molecules optimized at basis sets $\mathbf{1}$ and $\mathbf{2}$ indicates that interactions in the geometries optimized at basis set $\mathbf{1}$ are larger when compared to those seen with basis set $\mathbf{2}$. This result agrees with greater amount of interaction energies, $E_{\text {int }}$, determined at basis set $\mathbf{1}$ (table 1). Similarly, comparison of the values obtained for Pro- $\mathrm{Au}_{3}$ (a) and (b) indicates that magnitudes of sum of all charge transfer interaction in $\mathrm{Pro}_{-\mathrm{Au}_{3}}$ (a) is greater than that in $\mathrm{Pro}^{-\mathrm{Au}_{3}}$ (b). This result also agrees with our earlier conclusion that amide end of proline shows higher affinity to gold cluster.

\section{Conclusions}

Interaction of proline with $\mathrm{Au}_{3}$ has been described using energetic, geometrical and spectroscopic aspects. The metal interacts with proline through anchoring bonds, N-Au, O$\mathrm{Au}$ and a non-conventional $\mathrm{O}-\mathrm{H}$... Au hydrogen bond. Basis set dependence of interaction energies is noticed. Though trend of results provided by both the basis sets is the same, magnitudes of interaction energies obtained from basis set $\mathbf{2}$ are more reliable. Amide terminal of proline shows highest affinity to the cluster. Bond lengths of $\mathrm{N}-\mathrm{H}, \mathrm{C}=\mathrm{O}$ and $\mathrm{O}-\mathrm{H}$ in the amino acid are increased after complexation. The stretching mode of vibrations of these bonds undergoes red shift with respect to isolated proline structure. Interaction of cluster through amide end of proline induces a weak intramolecular H-bonding interaction, $\mathrm{N} 1-\mathrm{H} . . . \mathrm{O} 1 . \mathrm{NBO}$ analysis of the noncovalent interactions substantiates favourable interaction of proline with the cluster through its amide terminal.

Further study on interaction of gold with a proline associated with a secondary structure and a comparison with the present study is in progress.

\section{Acknowledgements}

We thank the Department of Science and Technology, New Delhi, Government of India, for financial support. One of the authors (SR) acknowledges CSIR for a fellowship.

\section{Electronic supplementary material}

Supplementary material pertaining to this article is available on the Bulletin of Materials Science Website (www.ias.ac.in/ matersci).

\section{References}

Agrawal B K, Agrawal S, Srivastava P and Singh S $2004 \mathrm{~J}$. Nanopart. Res. 6363

Ait-Haddou H, Wiskur S L, Lynch V M and Anslyn E V $2001 \mathrm{~J}$. Am. Chem. Soc. 12311296

Balasubramanian K and Liao D 1991 J. Chem. Phys. 945233

Balasubramanian K and Liao D 1992 J. Chem. Phys. 972548

Bucher S W, Gold J R and Freiser B S 1988 J. Chem. Phys. 883678

Černý J and Hobza P 2007 Phys. Chem. Chem. Phys. 95291

Cheeseman M A and Eyler J R 1992 J. Phys. Chem. 961082

Dennington R II, Todd K, Millam J, Eppinnett K, Lee Hovell W and Ray G 2003 GaussView3.09 (Shawnee Mission, KS: Semichem, Inc.)

Felice R D, Selloni A and Molinari E 2003 J. Phys. Chem. B107 1151

Fielicke A, von Helden G, Meijer G, Pedersen D B, Simard B and Rayner D M 2005 J. Am. Chem. Soc. 1278416

Frisch M J et al 2003 Gaussian03 (Pittsburg, PA: Gaussian, Inc.) revision B.05

Furche F, Ahlrichs R, Weis P, Jacob C, Gilb S, Bierweiler T and Kappes M M 2002 J. Chem. Phys. 1176982

Gilb S, Weis P, Furche F, Ahlrichs R and Kappes M M $2002 J$. Chem. Phys. 1164094

Hakkinen H, Moseler M and Landman U 2002 Phys. Rev. Lett. 89 03340

Hehre W J, Stewart R F and Pople J A 1969 J. Chem. Phys. 512657

Kim Y D, Fischer M and Gantefor G 2003 Chem. Phys. Lett. 377 170

Kohn W, Becke A D and Parr R G 1996 J. Phys. Chem. 10012974

Krúger D, Fuchs H, Rousseau D, Marx D and Parrinello M 2002 Phys. Rev. Lett. 89186402

Kryachko E S and Remacle F 2005a Nano Lett. 5735

Kryachko E S and Remacle F 2005b J. Phys. Chem. B109 22746

Kumar A, Mishra P C and Suhai S 2006 J. Phys. Chem. A110 7719

Lee H M, Ge M, Sahu B R, Tarakeshwar P and Kim K S 2003 J. Phys. Chem. B107 9994

Lee T H and Ervin K M 1994 J. Phys. Chem. 9810023

Lian L, Hackett P A and Rayner D M 1993 J. Chem. Phys. 992583

Moradi M, Babin V, Roland C, Darden T A and Sagui C 2009 Proc. Nat. Acad. Sci. USA 10620746

Niemietz M, Gerhardt P, Gantefor G and Kim Y D 2003 Chem. Phys. Lett. 38099

Pakiari A H and Jamshidi Z 2007 J. Phys. Chem. A111 4391

Read A E, Weinstock R B and Weinhold F 1985 J. Chem. Phys. 83 735

Remacle F and Kryachko E S 2005 J. Chem. Phys. 122044304

Riboh J C, Haes A J, McFarland A D, Ranjit C and Van Duyne R P 2003 J. Phys. Chem. B107 1772 
Shafai G S, Shetty S, Krishnamurty S, Shah V and Kanhere D G 2007 J. Chem. Phys. 126014704

Shafer-Peltier K E, Haynes C L, Glucksberg M R and Van Duyne R P 2003 J. Am. Chem. Soc. 125588

Sharma P, Sharma S, Mitra A and Singh H 2009 J. Biomol. Struct. Dyn. 2765

Shukla M K, Dubey M and Leszcynski 2008 ACS Nano 2227

Soule de Bas B, Ford M J and Cortie M B 2004 J. Mol. Struct.: Theochem. $\mathbf{6 8 6} 193$

Storhoff J J, Elghanian R, Mucic R C, Mirkin C A and Letsinger R L 1998 J. Am. Chem. Soc. 1201959
Sudeep P K, Joseph S T S and Thomas K G 2005 J. Am. Chem. Soc. 1276516

Walker A V 2005 J. Chem. Phys. 122094310

Weis P, Welz O, Vollmer E and Kappes M M 2004 J. Chem. Phys. 120677

Xiao L and Wang L 2004 Chem. Phys. Lett. 392452

Xiao L, Tollberg B, Hu X and Wang L 2006 J. Chem. Phys. 124 114309

Yuan D W, Wang Y and Zeng Z 2005 J. Chem. Phys. 122114310

Zheng J, Petty J T and Dickson R M 2003 J. Am. Chem. Soc. 125 7780 